\title{
The Impact of Parenteral Nutrition Support on Nutrition Care Outcomes of Hepatic Encephalopathy Patients in the Intensive Care Unit
}

\author{
MOHAMED E.A. EL-KOHAIL, M.Sc.; MOHAMED S. ABDEL-AZIZ, M.D.; ALFERID M. SAID, M.D. and \\ MAI M. ABDEL-AZIZ, M.D.
}

The Department of Anesthesiology and Intensive Care, Faculty of Medicine, Ain Shams University

\begin{abstract}
Background: Malnutrition and hepatic encephalopathy are two of the most common complications of cirrhosis and both have detrimental effects on outcome. Malnutrition is prevalent among cirrhotic patients and is an important prognostic factor. Etiologic factors include hypermetabolism, malabsorption, altered nutrient metabolism, and anorexia. It is a challenge to manage nutrition in cirrhotic patients because of alterations to metabolic and storage functions of the liver.
\end{abstract}

Aim of Study: The aim of this study is to evaluate the impact of a parenteral nutrition protocol on nutrition outcomes of hepatic encephalopathy patients admitted to the ICU.

Subjects and Methods: This prospective study was done on 76 hepatic encephalopathy patients with low tolerance or contraindications to enteral nutrition undergoing total parenteral nutrition starting from the day of admission and follow-up until discharge from ICU or 14 days as a length of the study. Daily assessment of the body functions was done and parenteral nutrition associated complications were recorded. 47 male patients and 39 female patients were suspected to the study with 53 patients older than 50 years and 23 patients younger than 50 years.

Results: $40.8 \%$ of patients were exposed to hospital related complications. $35.5 \%$ were exposed to one type of complications and $5.3 \%$ were exposed to two types or more. Hospital acquired pneumonia was the most complication affecting patients with $10.5 \%$ followed by CVC related infection with 7.9\% and also Hypoglycemic Attacks with $7.9 \%$ then urinary catheter-related infection with $6.6 \%$. Acute cholecystitis and thrombosis were the least complications affecting patients with $1.3 \%$ for each one.

Conclusions: Total parenteral nutrition does not influence the overall mortality rate of critically ill patients. It may reduce the complication rate, especially in malnourished patients.

Key Words: Hepatic encephalopathy - Total parenteral nutrition - Nutrition care outcome.

Correspondence to: Dr. Mohamed E.A. El-Kohail, E-Mail: mohamed.kohail@yahoo.com

\section{Introduction}

APPROPRTIATE nutritional support for critically ill patients is considered a marker of quality in ICU care and is associated with improved patient outcome. Despite this knowledge, it has been reported that $>40 \%$ of ICU patients might be malnourished, and the experience from ICUs internationally is that a substantial number of patients receive suboptimal nutrition [1].

Critical illness is typically associated with a catabolic stress state in which patients demonstrate a systemic inflammatory response coupled with complications of increased infectious morbidity, multiple-organ dysfunction, prolonged hospital stays, and disproportionate mortality. Over the past 3 decades, exponential advances have been made in the understanding of the molecular and biological effects of nutrients in maintaining homeostasis in the critically ill population [2].

Specific patient populations addressed by these expanded and updated guidelines include organ failure (pulmonary, renal, and liver), acute pancreatitis, surgical subsets (trauma, traumatic brain injury, open abdomen, and burns), sepsis, postoperative major surgery, chronic critically ill, and critically ill obese. These guidelines are directed toward generalized patient populations, but like any other management strategy in the ICU, nutrition therapy should be tailored to the individual patient [2].

Hepatic encephalopathy (HE) is defined as a reversible and metabolically induced neuropsychiatric complication, most commonly associated with cirrhosis, but may also be a complication of acute or chronic liver disease. The affected patients 
exhibit alterations in psychomotor functions, personality changes, cognitive impairment and disturbed sleep pattern [3].

Parenteral nutrition (PN) is indicated in alcoholic steatohepatitis (ASH) and in cirrhotic patients with moderate or severe malnutrition. PN should be started immediately when sufficient oral or enteral feeding is not possible. ASH and cirrhosis patients who can be sufficiently fed either orally or enterally, but who have to abstain from food over a period of more than 12 hours (including nocturnal fasting) should receive basal glucose infusion $(2-3 \mathrm{~g} / \mathrm{kg} / \mathrm{d})$. Total PN is required if such fasting periods last longer than $72 \mathrm{~h}$. As in other critically ill patients PN in acute liver failure is indicated when the patient is considered unlikely to resume normal oral nutrition within the next 57 days irrespective of current nutritional state. PN is helpful in patients who cannot be fed adequately by enteral nutrition [4].

Use of protocols and nutrition support teams has been shown to decrease $\mathrm{PN}$-associated complications. Permissive under-feeding has also been shown to be a potential short-term approach to avoid some of these complications [5].

\section{Material and Methods}

This study was conducted prospectively in Critical Care Units, El-Demerdash Hospital, Ain Shams in Cairo, Egypt during the period from March 2020 to August 2020. Study subjects included 76 critically ill hepatic encephalopathy patients in medical ICU.

The ethics committee of our institution approved the study protocol, and written informed consent was obtained from each patient's family.

\section{Inclusion criteria:}

- Patients with liver disease admitted to medical ICU because of hepatic encephalopathy.

- Cases with low tolerance or contraindications to enteral nutrition.

- Age $>18$ years of both sexes.

Exclusion criteria:

- Refusal of patient or his relatives to participate in the study.

- Patients with severe sepsis.

- Post-cardiac arrest patients.

- Patients with massive MI.

- Patients with cardiac cirrhosis, renal impairment or primary pulmonary disease.
- Patients with other causes of conscious deterioration.

Methods:

All selected individuals were subjected to the following:

- Full medical history taking.

- Full clinical examination:

${ }^{\circ}$ General examinations (GCS, Body Weight and $\mathrm{BMI}$ ).

${ }^{\circ}$ Specific examinations as neurological examinations (response to painful stimuli and muscle strength); examination of the eye, abdomen, chest, heart and extremities.

${ }^{\circ}$ Vital signs assessment (temperature, heart rate, respiratory rate and non-invasive blood pressure).

${ }^{\circ}$ Determination of full laboratory investigations at the date of admission as a baseline:

- Coagulation profile (PT, PTT and INR) daily.

- Renal function tests (blood urea, serum creatinine, and eGFR) daily.

- Liver function tests (ALT, AST, serum proteins, serum albumin and serum bilirubin) daily.

- Serum ammonia daily.

- Complete blood picture daily.

- Blood lipid profiles on admission and on days five, ten, and fourteen.

- Random blood glucose on admission and every 2 hours.

- Cultures if needed.

- Arterial blood gases (ABG).

- Urinary urea nitrogen daily.

- Electrolytes (Na+, K+, Cl-, $\mathrm{Ca} 2+, \mathrm{Mg} 2+$ and $\mathrm{PO} 42)$ on admission and repeating them after 46 hours.

- Doing radiological echocardiography, plain Xray chest and ECG.

- Central venous catheter insertion.

\section{Interventions:}

- Antimicrobial regimens were applied according to ICU protocol.

- Parenteral nutrition protocol for hepatic encephalopathy patients was applied as follows:

General:

- TPN was considered if EN is contraindicated.

\section{Energy:}

- Basal Metabolic Rate (BMR) was estimated using the following equations: 
Men: $\mathrm{BMR}=88.362+(13.397 \mathrm{x}$ weight in $\mathrm{kg})$ $+(4.799 \mathrm{x}$ height in $\mathrm{cm})-(5.677 \mathrm{x}$ age in years $)$

Women: $\mathrm{BMR}=447.593+(9.247 \mathrm{x}$ weight in $\mathrm{kg})+(3.098 \mathrm{x}$ height in $\mathrm{cm})-(4.330 \mathrm{x}$ age in years)

- Energy was provided to cover $1.3 \times$ x BMR.

- Glucose was given to cover $60 \%$ of non-protein energy requirements.

- 10 units of human insulin Actrapid per 50g of glucose were added.

- Lipid emulsions were given to cover $40 \%$ of nonprotein energy requirements.

Protein:

- Human albumin at $80 \mathrm{~g} / \mathrm{d}$ was given.

- Amino acids at $1.3 \mathrm{~g} / \mathrm{kg} / \mathrm{d}$ were provided.

- Solutions rich in branched-chain amino acids (BCAA) and low in aromatic amino acids (AAA) were used.

- In acute or sub-acute liver failure, amino acids at $1 \mathrm{~g} / \mathrm{kg} / \mathrm{d}$ were provided.

\section{Micronutrients:}

- $20 \mathrm{mEq}$ of potassium chloride per $50 \mathrm{~g}$ of glucose were added.

- Water soluble vitamins and trace elements from the first day of PN were given.

- Vitamin B1 prior to starting glucose infusion was administered.

\section{Monitoring:}

- RBS determinations every 2 hours were done.

- Phosphate, sodium, potassium and magnesium levels were monitored keeping them in normal range.

- Fluid balance was maintained guided with CVP and urine output.

- Daily assessment of body functions and followup until discharge from ICU.

\section{Results}

This prospective study was done on 76 hepatic encephalopathy patients with low tolerance or contraindications to enteral nutrition undergoing total parenteral nutrition starting from the day of admission and follow-up until discharge from ICU or 14 days as a length of the study.

Daily assessment of the body functions was done and parenteral nutrition associated complications were recorded.
47 male patients and 39 female patients were suspected to the study with 53 patients older than 50 years and 23 patients younger than 50 years Table (1), Figs. $(1,2)$.

Table (1): Distribution of the studied cases according to demographic data $(n=76)$.

\begin{tabular}{ccc}
\hline & No. & $\%$ \\
\hline Age (years): & & \\
$\leq 50$ & 23 & 30.3 \\
$>50$ & 53 & 69.7 \\
Min.-Max. & \multicolumn{2}{c}{$42.0-83.0$} \\
Mean \pm SD. & \multicolumn{2}{c}{$57.0 \pm 9.16$} \\
Median (IQR) & $56.50(49.0-64.0)$ \\
Sex: & \multicolumn{2}{|}{48.7} \\
Male & 37 & 51.3 \\
Female & 39 &
\end{tabular}

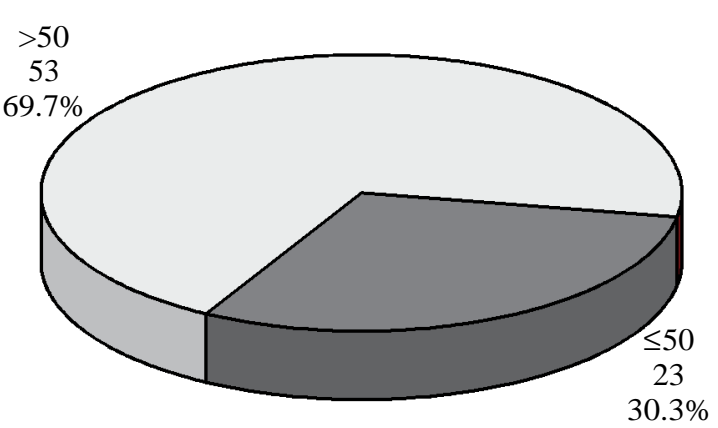

Fig. (1): Distribution of the studied cases according to age (years) $(n=76)$.

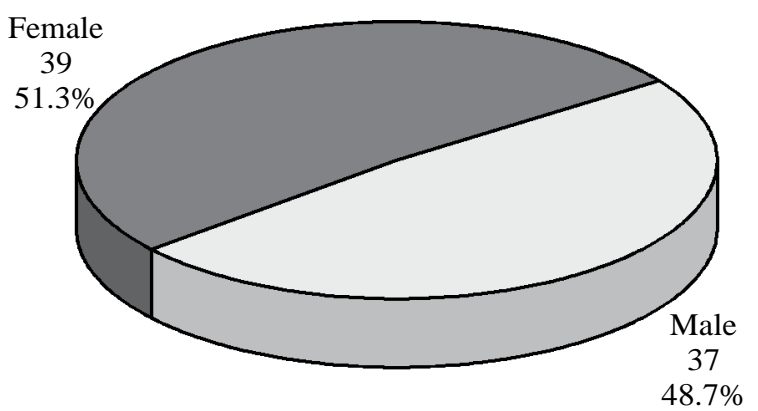

Fig. (2): Distribution of the studied cases according to sex $(n=76)$.

As regarding the parenteral nutrition related complications Table (2) shows:

$40.8 \%$ of patients were exposed to hospital related complications. $35.5 \%$ were exposed to one type of complications and $5.3 \%$ were exposed to two types or more. Hospital acquired pneumonia was the most complication affecting patients with $10.5 \%$ followed by CVC related infection with 7.9\% and also Hypoglycemic Attacks with 7.9\% then urinary catheter-related infection with $6.6 \%$. Acute cholecystitis and thrombosis were the least complications affecting patients with $1.3 \%$ for each one Table (2), Figs. $(3,4)$. 
Table (2): Distribution of the studied cases according to hospital related complications $(n=76)$.

\begin{tabular}{lll}
\hline Hospital related complications & No. & $\%$ \\
\hline No & 45 & 59.2 \\
Yes & 31 & 40.8 \\
One type & 27 & 35.5 \\
Two type & 4 & 5.3 \\
HAP & 8 & 10.5 \\
CVC related infection & 6 & 7.9 \\
Urinary catheter-infection & 5 & 6.6 \\
Skin infection & 3 & 3.9 \\
Thrombosis & 1 & 1.3 \\
Acute cholecystitis & 1 & 1.3 \\
Hyperglycemic Attacks & 5 & 6.6 \\
Hypoglycemic Attacks & 6 & 7.9 \\
\hline
\end{tabular}

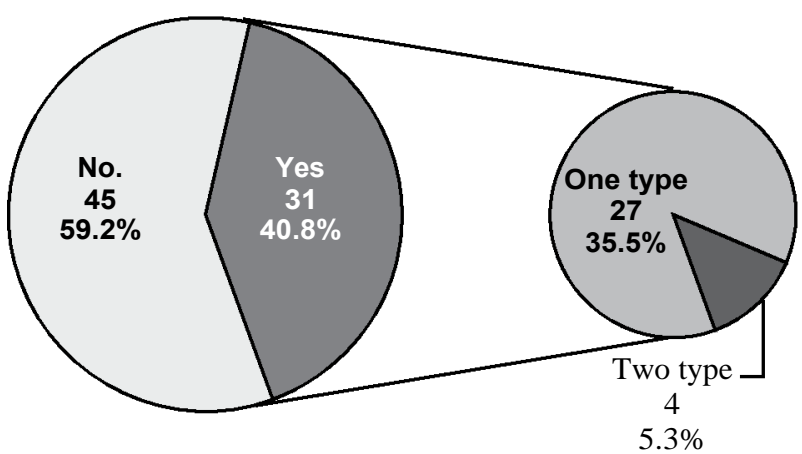

Fig. (3): Distribution of the studied cases according to hospital related complications $(n=76)$.

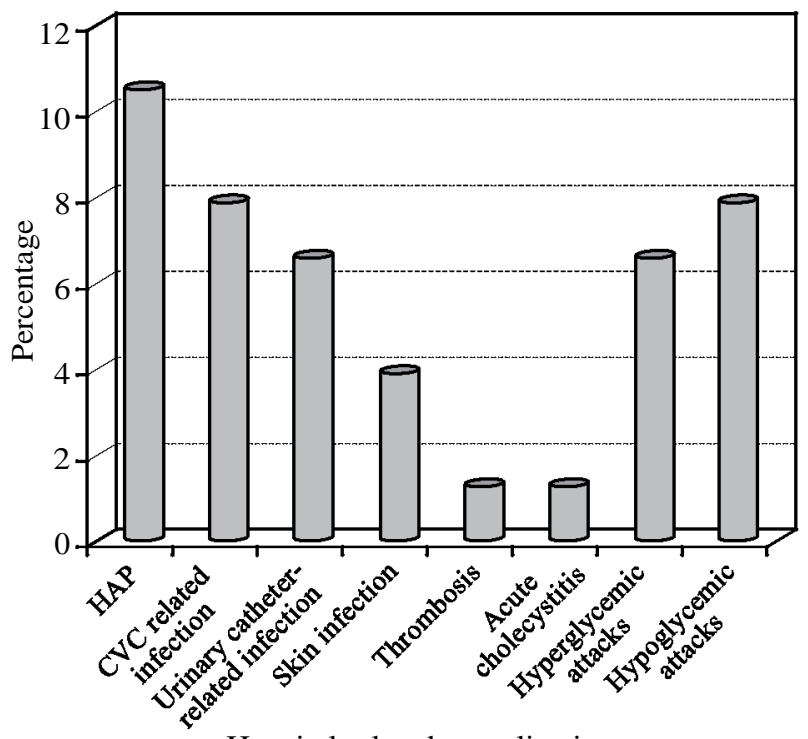

Hospital related complications

Fig. (4): Distribution of the studied cases according to hospital related complications $(n=76)$.

Comparison between body weight on day 1 and day 14 Table (3) shows:

There were statistically significant differences between the studied patients on day 1 and day 14 with median body weight of $87 \mathrm{~kg}$ on day 1 and $82 \mathrm{~kg}$ on day 14 Table (3) Fig. (5).
Table (3): Comparison between day 1 and day 14 according to Body Weight $(\mathrm{kg})(\mathrm{n}=65)$.

\begin{tabular}{lllll}
\hline $\begin{array}{l}\text { Body Weight } \\
(\mathrm{kg})\end{array}$ & $\begin{array}{c}\text { Day 1 } \\
(\mathrm{n}=65)\end{array}$ & $\begin{array}{l}\text { Day 14 } \\
(\mathrm{n}=65)\end{array}$ & $t$ & $p$ \\
\hline Min.-Max. & $59.0-112.0$ & $53.0-111.0$ & & \\
Mean \pm SD. & $84.26 \pm 11.90$ & $82.29 \pm 12.96$ & $3.515^{*}$ & $0.001^{*}$ \\
Median (IQR) & $\begin{array}{l}87.0 \\
(76.0-90.0)\end{array}$ & $\begin{array}{l}82.0 \\
(73.0-90.0)\end{array}$ & & \\
Decreases & \multicolumn{2}{c}{$2.43 \pm 5.44$} & & \\
\hline
\end{tabular}

$t$ : Paired $t$-test.

$p: p$-value for comparing between the day 1 and day 14 .

$*$ : Statistically significant at $p \leq 0.05$.

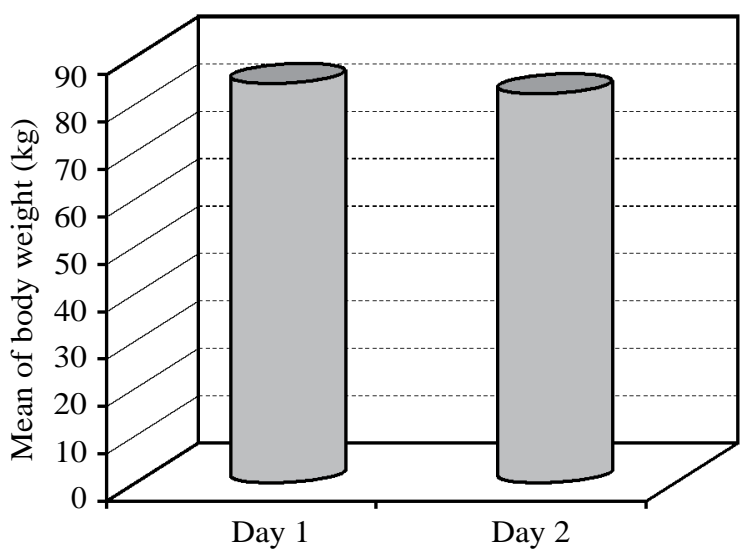

Fig. (5): Comparison between day 1 and day 14 according to body weight $(\mathrm{kg})(\mathrm{n}=65)$.

Comparison between the three studied periods according to Albumin Table (4) shows:

There were no statistically significant differences of albumin of day 1 and day 7 but there were statistically significant differences of albumin of day 7 and day 14 and also of day 1 and day 14 Table (4) Fig. (6).

Table (4): Comparison between the three studied periods according to Albumin (g/dl) $(\mathrm{n}=65)$.

\begin{tabular}{|c|c|c|c|c|c|}
\hline $\begin{array}{l}\text { Albumin } \\
\text { (g/dl) }\end{array}$ & Day 1 & Day 7 & Day 14 & $\mathrm{~F}$ & $p$ \\
\hline Min.-Max. & $1.50-3.50$ & $1.60-3.20$ & $2.20-3.30$ & & \\
\hline Mean \pm SD & $2.61 \pm 0.49$ & $2.68 \pm 0.41$ & $2.89 \pm 0.29$ & $18.917 *$ & $<0.001 *$ \\
\hline Median (IQR) & $\begin{array}{l}2.60 \\
(2.30-2.90)\end{array}$ & $\begin{array}{l}2.70 \\
(2.40-3.0)\end{array}$ & $\begin{array}{l}3.0 \\
(2.80-3.10)\end{array}$ & & \\
\hline $\begin{array}{l}\text { Sig.bet. } \\
\text { periods }\end{array}$ & \multicolumn{5}{|c|}{$p 1=0.335, p 2<0.001 *, p 3=0.002 *$} \\
\hline $\begin{array}{l}\text { Increases } \\
\quad \text { (day } 1 / \text { day } 14\end{array}$ & \multicolumn{5}{|c|}{$13.31 \pm 17.97$} \\
\hline
\end{tabular}

F: F-test (ANOVA) with repeated measures.

Sig. bet. periods was done using Post Hoc Test (adjusted Bonferroni). $p: p$-value for comparing between the three studied periods. pl: $p$-value for comparing between the day 1 and day 7. 2: $p$-value for comparing between the day 1 and day 14 . 3: $p$-value for comparing between the day7 and day 14 . *: Statistically significant at $p \leq 0.05$. 


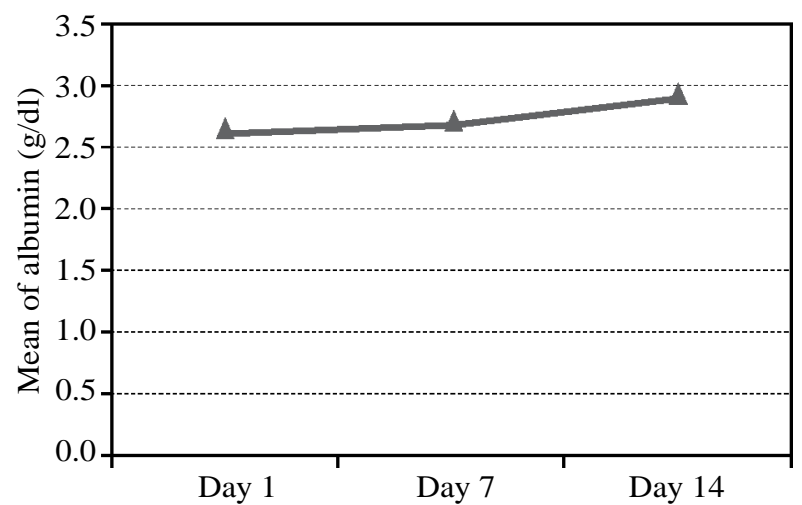

Fig. (6): Comparison between the three studied periods according to albumin $(\mathrm{g} / \mathrm{dl})(\mathrm{n}=65)$.

Comparison between day 1 and day 14 according to Cholesterol Table (5) shows:

There were no statistically significant differences of cholesterol of day 1 and day 14 Table (5) Fig. (7).

Table (5): Comparison between day 1 and day 14 according to Cholesterol $(\mathrm{mg} / \mathrm{dl})(\mathrm{n}=65)$.

\begin{tabular}{lllcc}
\hline $\begin{array}{l}\text { Cholesterol } \\
(\mathrm{mg} / \mathrm{dl})\end{array}$ & \multicolumn{1}{c}{ Day 1 } & Day 14 & $\mathrm{Z}$ & $p$ \\
\hline Min.-Max. & $139.0-250.0$ & $145.0-240.0$ & & \\
Mean \pm SD. & $180.57 \pm 23.31$ & $182.28 \pm 20.13$ & 0.782 & 0.434 \\
Median (IQR) & $\begin{array}{l}176.0 \\
(167.0-188.0)\end{array}$ & $\begin{array}{l}178.0 \\
(166.0-190.0)\end{array}$ & & \\
Increases & $2.14 \pm 14.34$ & & \\
\hline
\end{tabular}

$\mathrm{Z}$ : Wilcoxon signed ranks test.

$p$ : $p$-value for comparing between the day 1 and day 14 .

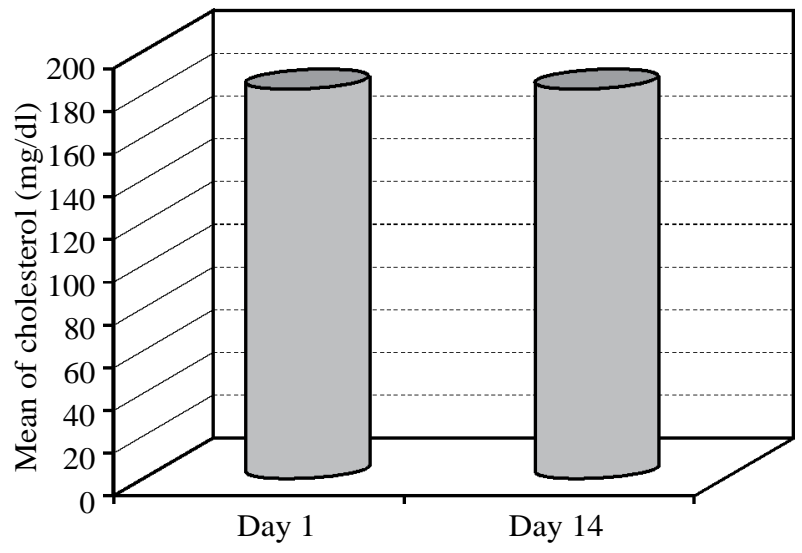

Fig. (7): Comparison between day 1 and day 14 according to cholesterol $(\mathrm{mg} / \mathrm{dl})(\mathrm{n}=65)$.

Distribution of the studied cases according to Length of stay and ICU mortality Table (6) shows:

ICU mortality was $14.5 \%$ and $85.5 \%$ of patients were still alive after 14 days of ICU stay as a length of the study. $100 \%$ of patients who were still alive stayed in ICU more than 14 days from the date of admission Table (6) Figs. $(8,9)$.
Table (6): Distribution of the studied cases according to Length of stay and ICU mortality $(n=76)$.

\begin{tabular}{ccc}
\hline No. & $\%$ \\
\hline \multicolumn{3}{c}{ Length of stay: } \\
65 & $<14$ days & 14.5 \\
& $>14$ days & 85.5 \\
& ICU mortality: \\
65 & Alive & 85.5 \\
11 & Died & 14.5 \\
\hline
\end{tabular}

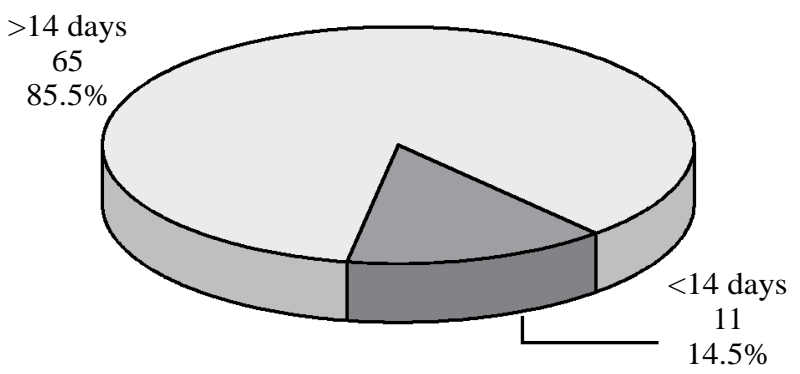

Fig. (8): Distribution of the studied cases according to length of stay $(n=76)$.

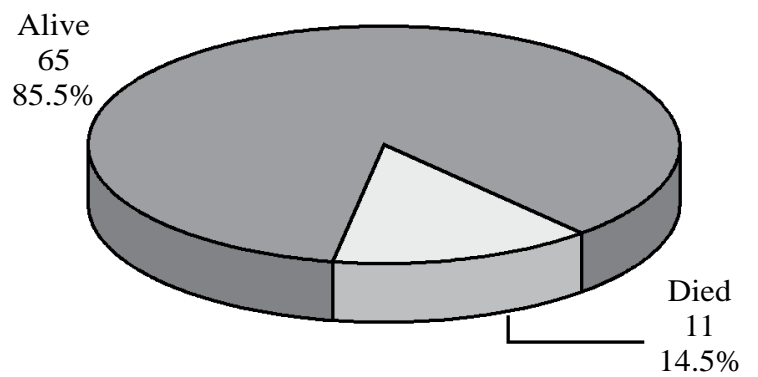

Fig. (9): Distribution of the studied cases according to ICU mortality $(n=76)$.

\section{Discussion}

Undernutrition is an important risk factor for infections and poor outcome in the intensive-care unit (ICU). New guidelines recommend the addition of parenteral nutrition to enteral nutrition to supply patients in ICU. Parenteral nutrition initiated after 1 week or earlier (after 2-3 days in ICU).

Nutritional support has become a standard of care for hospitalized patients, but whether total parenteral nutrition (TPN) affects morbidity and mortality is unclear. This present study was established to examine the relationship between TPN and complications and mortality rates in critically ill patients.

210 titles, abstracts, and papers were reviewed in a computerized search of published research on MEDLINE, personal files, and review of relevant reference lists. Primary studies were included if they were randomized clinical trials of critically ill patients that evaluated the effect of TPN (com- 
pared with standard care) on complication and mortality rates. Studies comparing TPN with enteral nutrition were excluded. There were 26 randomized trials of 2211 patients comparing the use of TPN with standard care (usual oral diet plus intravenous dextrose) in surgical and critically ill patients. When the results of these trials were aggregated, TPN had no effect on mortality (risk ratio [RR], $1.03 ; 95 \%$ ). Patients who received TPN tended to have a lower complication rate, but this result was not statistically significant (RR, $0.84 ; 95 \%$ ). The studies including only malnourished patients were associated with lower complication rates but no difference in mortality when compared with studies of non-malnourished patients. Total parenteral nutrition does not influence the overall mortality rate of surgical or critically ill patients. It may reduce the complication rate, especially in malnourished patients [6].

In this present study, 76 critically ill hepatic encephalopathy patients received total parenteral nutrition from the day of admission. Cases with low tolerance or contraindications to enteral nutrition were selected provided that being older than 18 years of sexes ( 37 males and 39 females), (53 patients older than 50 years and 23 patients younger than 50 years). Patients with severe sepsis, postcardiac arrest patients, patients with massive MI, patients with cardiac cirrhosis, patients with renal impairment or primary pulmonary disease and patients with other causes of conscious deterioration were excluded. Statistical analysis was done showed that $40.8 \%$ of the patients were exposed to hospital related complications. $35.5 \%$ were exposed to one type of complications and $5.3 \%$ were exposed to two types or more. Hospital acquired pneumonia was the most complication affecting the patients with $10.5 \%$ followed by CVC related infection with $7.9 \%$ and also Hypoglycemic Attacks with $7.9 \%$ then urinary catheter-related infections with $6.6 \%$. Acute cholecystitis and thrombosis were the least complications affecting patients with $1.3 \%$ for each one.

This study showed that there were no significant differences between the studied patients as regard nosocomial infections between first and second weak. On the other hand, Claudia Heidegger and colleagues reported that the use of parenteral nutrition in patients unable to achieve adequate nutrient intake in the first 3 days of intensive-care unit (ICU) stay results in fewer infections between day 9 and day 28 compared with patients who had enteral nutrition only. PN was provided on day 4, and the SPN group had total infectious events between day 4 and day 8 more than between day
9 and day 28. Although the authors show that supplemental parenteral nutrition (SPN) is associated with decreased infectious complications between day 9 and day 28 in the intensive-care unit (ICU), they also observe a trend in increasing infectious complications between day 4 and day 8 (34\% vs $28 \%$ ]). The total number of infectious events during and after the intervention is important. The greater risk of pneumonia occurring between day 4 and day 8 in the SPN group (35 vs 28 patients) suggests a possible limitation of early SPN. Hence, SPN for patients who can be fed enterally up to $60-80 \%$ of target might not provide any clinical benefit, and cannot be recommended [7].

Claudia Heidegger and colleagues reported that $23 \%$ of patients who received parenteral nutrition had one or more nosocomial infections in the first 5 days of parenteral nutrition administration and $15 \%$ had nosocomial infection in the following 20 days with a total percentage of $37 \%$ patients with nosocomial infections from day 1 of parenteral nutrition administration to the last day of the study. In our present study the number of patients who had nosocomial infections is 22 patients (28.9\%) in the duration of 14 days as a length of the study with no significant differences between the studied patients as regard nosocomial infections between first and second weak [7].

In our present study $6.6 \%$ of studied patients had hyperglycemic attacks (blood glucose $>180 \mathrm{mg} / \mathrm{dl}$ ), $4.4 \%$ of them had complicated with hospital acquired pneumonia. Francisco $\mathrm{J}$ and his colleges made a retrospective study of medical and surgical patients receiving TPN during the period of 1 January 2006 to 31 December 2006 at Grady Memorial Hospital in Atlanta, Georgia. They collected information on demographics, blood glucose on admission, pre-TPN, within $24 \mathrm{~h}$, and during days 2-10 of TPN. Subjects included a total of 276 patients receiving TPN for a mean duration of $15 \pm 24$ days. A blood glucose within $24 \mathrm{~h}$ of $>180$ $\mathrm{mg} / \mathrm{dl}$ was associated with increased risk of pneumonia [8].

As regarding ICU mortality, Heyland DK and his colleges reported that total parenteral nutrition does not influence the overall mortality rate of critically ill patients. It may reduce the complication rate, especially in malnourished patients. In this study the mortality rate is $14.5 \%, 11$ of 76 patients were died in ICU and 65 patients were still alive till the last day of the study [6].

As regarding body weight, there were statistically significant differences between the studied 
patients on day 1 and day 14 with median body weight of $87 \mathrm{~kg}$ on day 1 and $82 \mathrm{~kg}$ on day 14 . The minimum body weight on admission was $59 \mathrm{~kg}$ and the maximum body weight was $112 \mathrm{~kg}$. On day 14 the minimum body weight was $53 \mathrm{~kg}$ and the maximum body weight was $111 \mathrm{~kg}$ with a decrease of $5.44 \pm 2.43$ and $p$-value of 0.001 . This study shows that total parenteral nutrition in critically ill patients result in weight loss in the majority of patients.

Karlawish $\mathbf{J}$ and his colleges tried to assess whether the serum albumin level rises in patients given total parenteral nutrition (TPN). All randomized controlled studies of TPN for at least 7 days versus oral therapy were reviewed. Data on serum albumin had to be available to be acceptable for analysis. None of the reported studies showed a significant rise in serum albumin with TPN when compared to controls. The mean change in serum albumin levels for all of the studies was $-0.3 \mathrm{~g} / \mathrm{dl}$ in the TPN group and $-0.3 \mathrm{~g} / \mathrm{dl}$ in the control group. In published randomized controlled studies of TPN versus oral diet, there is no significant increase in serum albumin levels in those receiving TPN or decrease in serum albumin in controls. Their study does not support the serum albumin level as a nutritional marker in critically ill patients [9].

In this study the median serum albumin level on admission is $2.6 \mathrm{~g} / \mathrm{dl}$ with a minimum median level of $2.3 \mathrm{~g} / \mathrm{dl}$ and maximum median level of $2.9 \mathrm{~g} / \mathrm{dl}$. On the day 7 the median serum albumin level is $2.6 \mathrm{~g} / \mathrm{dl}$ with a minimum median level of $2.4 \mathrm{~g} / \mathrm{dl}$ and maximum median level of $3 \mathrm{~g} / \mathrm{dl}$. On the day 14 , the median serum albumin level is $3 \mathrm{~g} / \mathrm{dl}$ with a minimum median level of $2.8 \mathrm{~g} / \mathrm{dl}$ and maximum median level of $3.1 \mathrm{~g} / \mathrm{dl}$. There were no statistically significant differences of albumin of day 1 and day 7 ( $p$-value 0.335 ) but there were statistically significant differences of albumin of day 7 and day 14 ( $p$-value 0.002 ) and also of day 1 and day 14 ( $p$-value) 0.001 .

As regarding serum cholesterol in our present study, the median serum cholesterol level on admission is $176 \mathrm{mg} / \mathrm{dl}$ with a minimum median level of $167 \mathrm{mg} / \mathrm{dl}$ and maximum median level of $188 \mathrm{mg} / \mathrm{dl}$. The median serum cholesterol level on day 14 is $178 \mathrm{mg} / \mathrm{dl}$ with a minimum median level of $166 \mathrm{mg} / \mathrm{dl}$ and maximum median level of $190 \mathrm{mg} / \mathrm{dl}$. There were no statistically significant differences of cholesterol of day 1 and day 14 ( $p$ value 0.434 ) with an increase of $14.34 \pm 2.14$. On the other hand, $\mathrm{T}$ Tashiro and his colleges studied eight patients for lipoprotein profiles over a period of 3-7 weeks. Patients received total parenteral nutrition (TPN), including $1000 \mathrm{ml} /$ day of Intralipid
$10 \%$. Intravenous administration of Intralipid $10 \%$ caused a marked increase of LDL, together with increases of phospholipid and cholesterol, especially free cholesterol. Triglyceride, VLDL, and HDL remained within the normal [10].

\section{Conclusion:}

Total parenteral nutrition does not influence the overall mortality rate of critically ill patients. It may reduce the complication rate, especially in malnourished patients.

\section{References}

1- WIKJORD K., DAHL V. and SøVIK S.: Effects on nutritional care practice after implementation of a flow chart-based nutrition support protocol in an intensive care unit. Nurs. Open, 4: 282-291, 2017.

2- McCLAVE S.A., TAYLOR B.E., MARTINDALE R.G., WARREN M.M., JOHNSON D.R., BRAUNSCHWEIG C., McCARTHY M.S., DAVANOS E., RICE T.W., CRESCI G.A., GERVASIO J.M., SACKS G.S., ROBERTS P.R. and COMPHER C.: Guidelines for the Provision and Assessment of Nutrition Support Therapy in the Adult Critically Ill Patient: Society of Critical Care Medicine (SCCM) and American Society for Parenteral and Enteral Nutrition (A.S.P.E.N.). J. Parent Enter Nutr., 40 (2): 159211. meta-analysis JAMA, 2016.

3- STEPANOVA M., MISHRA A., VENKATESAN C. and YOUNOSSI Z.M.: In-hospital mortality and economic burden associated with hepatic encephalopathy in the United States from 2005 to 2009. Clin. Gastroenterol. Hepatol., 10: 1034-1041, 2012. e1. doi: 10.1016/j.cgh. 2012. 05.016.

4- PLAUTH M.: the European e-Journal of Clinical Nutrition and Metabolism Volume 5, Issue 2, April, 104-106, 2010.

5- WILSON N. and BLACKETT B.: Parenteral nutrition: Considerations for practice. May; Suppl ]\:S 16, S 18-9, 2012.

6- HEYLAND D.K., DHALIWAL R., DROVER J.W., GRAMLICH L. and DODEK P.: Canadian clinical practice guidelines for nutrition support in mechanically ventilated, critically ill adult patients. J. Parenter Enteral Nutr., 27: pp. 355-373, 2003.

7- HEIDEGGER C.P., BERGER M.M. and GRAF S.: Optimisation of energy provision with parenteral nutrition in critically ill patients. Lancet, 381: 385-93, 2013.

8- FRANCISCO J. PASQUE, M.D., RONNIE SPIEGELMAN, Ph.D., MEGAN McCAULEY, M.D., DAWN SMILEY, M.D., DENISE UMPIERREZ B.A., RACHEL JOHNSON B.A., MARY RHEE, M.D., CHELSEA GATCLIFFE B.A., ERICA LIN B.A., ERICA UMPIERREZ, LIMIN PENG, Ph.D. and GUILLERMO E. UMPIERREZ M.: Diabetes Care. Hyperglycemia During Total Parenteral Nutrition. Apr., 33 (4): 739-741, 2010.

9- KARLAWISH J., CRAIG R.M. and KORETZ R.: The effect of total parenteral nutrition on serum albumin. J. Clin. Gastroenterol., 19 (4): 300-302, 1994.

10- Tashiro T., Mashima Y., Yamamori H., Okui K.: Alteration of lipoprotein profile during total parenteral nutrition with intralipid 10\% Nov-Dec., 10 (6): 622-6, 2006. 


\section{تقييم تأثير التغذية الوريدية على النتائج التغذوية الفية

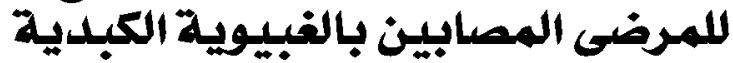 فى وحلدة العنايلة المركزة الفيورة}

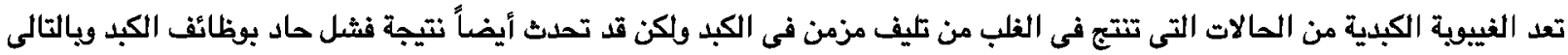

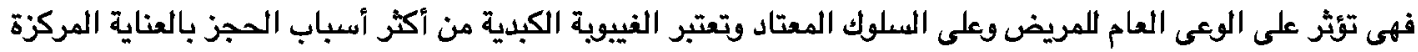

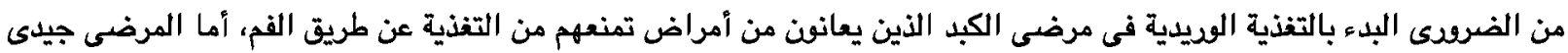

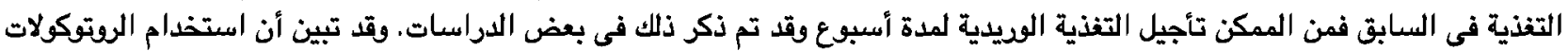
وفرق دعم التغذية يساهم فى تقليل مضاعفات التغذية الوريدية.

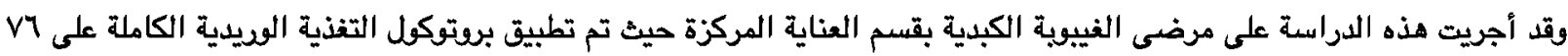

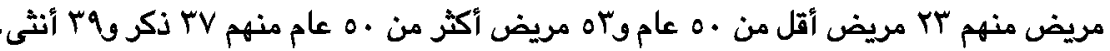

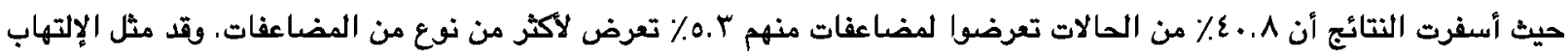

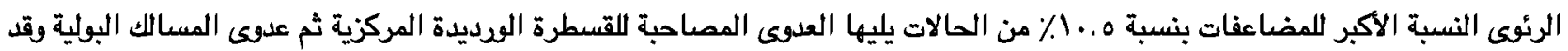

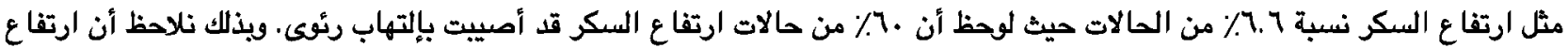

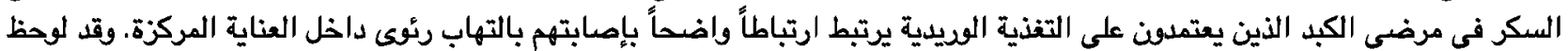

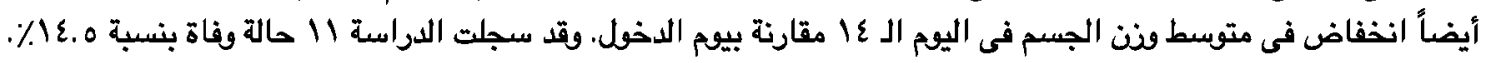

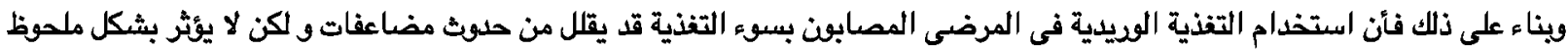

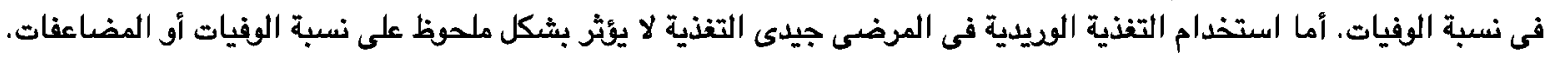

